\title{
GNT-Cyst 2.0 - Um Software Educacional para o Ensino de Genética
}

\author{
Eryck P. da Silva ${ }^{1}$, Carla A.D.M. Delgado ${ }^{1}$, Fábio F. Sampaio ${ }^{2}$ \\ ${ }^{1}$ Instituto de Matemática - Departamento de Ciência da Computação \\ Universidade Federal do Rio de Janeiro (UFRJ) \\ ${ }^{2}$ Instituto Tércio Pacitti de Aplicações e Pesquisas Computacionais - NCE \\ Universidade Federal do Rio de Janeiro (UFRJ) \\ eryckpedro@ufrj.br, carla@dcc.ufrj.br, ffs@nce.ufrj.br
}

\begin{abstract}
Resumo. Este artigo descreve o desenvolvimento do GNT-Cyst 2.0, um ambiente de simulação para o ensino-aprendizagem de genética a partir das Leis de Mendel. $O$ simulador permite explorar os conceitos fundamentais da genética de forma interativa e visual, possibilitando uma compreensão em um nível diferente do que somente é obtido quando abordado no papel. Os resultados obtidos pelas validações realizadas com alunos e professores do ensino fundamental e médio também são descritos, e mostram um interesse positivo que a tecnologia oferece como complemento à sala de aula.
\end{abstract}

\section{Introdução}

Os conceitos e fundamentos sobre a transmissão de características hereditárias ocorrem no fim do ensino fundamental e são formalizados no decorrer do ensino médio, como está proposto nos Parâmetros Curriculares Nacionais (PCN) [BERGER FILHO et al. 1996] e também abordado pelas Orientações Educacionais Complementares aos Parâmetros Curriculares Educacionais (PCN+) [MINISTÉRIO DA EDUCAÇÃO ].

Uma pesquisa realizada por docentes da Universidade Federal do Rio Grande do Norte [IORIOPETROVICH 2014] apontou que o tema de genética e Leis de Mendel é o segundo mais complicado de ser lecionado no ensino básico de biologia, sendo citologia o que ocupa o primeiro lugar. As razões da dificuldade são o nível de abstração do tema, a falta de infraestrutura escolar para exploração e a exigência de conhecimentos de outros conceitos que não pertencem à biologia, como matemática, por exemplo.

O objetivo do GNT-Cyst 2.0 é propor um ambiente de simulação que permita explorar os conceitos da primeira e segunda Lei de Mendel por diferentes usuários, que são principalmente alunos e professores do ensino fundamental e médio.

\subsection{Justificativa Teórica e Pedagógica}

De um modo geral, o computador em sala de aula pode ser utilizado de três formas distintas: para o ensino de computação, em que o aluno experiencia conceitos teóricos sobre o computador; no ensino através do computador onde os principais conceitos e exercícios de uma determinada disciplina são apresentadas aos alunos numa determinada sequência didática e no ensino com o computador, em que o professor, o aluno e o computador são "parceiros"no processo de ensino e aprendizagem, trabalhando em novos modelos de sala de aula mais interativas [VALENTE 1998]. 
VI Congresso Brasileiro de Informática na Educação (CBIE 2017)

Anais dos Workshops do VI Congresso Brasileiro de Informática na Educação (WCBIE 2017)

O GNT-Cyst 2.0 foi construído como um simulador, podendo portanto ser enquadrado na modalidade de ensino com o computador.

Simuladores são programas que propõem exibir um ambiente de simplificação de cenários do mundo real. São muito úteis para trabalhos em situações que são de difícil realização, como as que oferecem custos e riscos.

A principal vantagem no uso de simuladores em sala de aula é a de permitir aos alunos construírem e testarem hipóteses sobre fenômenos da vida real relacionados a diferentes tópicos das disciplinas do currículo escolar. Trabalhos em grupo são também possíveis com simuladores como o GNT-Cyst 2.0, onde cada equipe pode testar um pensamento diferente e refletir sobre seus erros, caso o resultado não saia como esperado.

\subsection{Justificativa Situacional}

Durante o desenvolvimento do GNT-Cyst 2.0, outros softwares com o mesmo propósito foram pesquisados com o objetivo de conhecer o cenário atual de como o assunto tem sido abordado. Alguns dos principais resultados encontrados são descritos abaixo.

O Programa GBOL [CRUZ, C.D. et al ] (Genética Básica OnLine) foi desenvolvido pela Universidade Federal de Viçosa com o propósito de auxiliar o ensino e aprendizagem de Genética Básica. Por abordar, em sua maioria, temas mais complexos do assunto, ele é voltado para o ensino superior, podendo ser utilizado no ensino médio em alguns tópicos. A apresentação do conteúdo é realizada com textos, imagens e animações de simulações prontas, permitindo pouca interação com o usuário.

O software Show da Genética [MONTEIRO MARTINEZ et al. 2008] tem a proposta de incentivar o ensino e aprendizagem do conteúdo por meio de um jogo de perguntas e respostas. Ele foi desenvolvido pela Universidade do Estado de São Paulo. Construído no Microsoft PowerPoint, ele utiliza links entre os slides de forma a avaliar se o jogador escolheu alternativa certa ou não. Essa abordagem também permite que um professor faça edições, colocando novas questões. Segundo os autores, ele pode ser utilizado por alunos do ensino fundamental e médio.

Pesquisando fora do Brasil, o StarGenetics [OEIT - MIT ], desenvolvido pelo MIT (Massachusetts Institute of Technology), é um simulador de cruzamentos mendelianos. Ele permite que os usuários combinem indivíduos com certas características a fim de determinar como elas se comportam, indo muito além dos itens abordados pelo GNTCyst 2.0. No entanto, dado o número excessivo de parâmetros iniciais, a sua utilização acaba se tornando um pouco complexa, dificultando o seu uso por estudantes do ensino fundamental. Uma outra desvantagem do ambiente é o fato de estar disponível apenas em língua inglesa.

Os resultados encontrados indicam que há projetos para auxiliar o ensinoaprendizagem de genética - o que reforça o argumento sobre a dificuldade, por parte dos alunos, na compreensão do tema. Desta forma, o desenvolvimento do GNT-Cyst 2.0 se justifica principalmente por: (i) permitir uma maior interação do usuário com diferentes aspectos da genética; (ii) apresentação do conteúdo em diferentes módulos, mais fortemente relacionados ao currículo do ensino fundamental e médio. 
VI Congresso Brasileiro de Informática na Educação (CBIE 2017)

Anais dos Workshops do VI Congresso Brasileiro de Informática na Educação (WCBIE 2017)

\section{Desenvolvimento}

A função principal do software é permitir a simulação de combinações genéticas para representar a primeira e a segunda Lei de Mendel. Ele está dividido em módulos específicos em acordo com o currículo abordado no ensino fundamental e médio.

\subsection{Visão Geral}

O GNT-Cyst 2.0 foi construído na Game Engine ${ }^{1}$ Unity3D [Unity Technologies ]. A escolha deste programa é devido a experiência que o primeiro autor deste trabalho já possuía com a mesma, além de que, atualmente, a empresa que a criou mantém a licença informando que o que você criar é livre de royalties, ou seja, não precisa pagar para divulgação.

O software foi construído fortemente sobre o conceito de cenas, presentes na Unity3D. Cenas são cenários fechados em que são colocados diversos mecanismos que tem o propósito de interagir com o jogador. A estrutura disponibilizada por esse tipo de arquitetura permite a concepção de um ambiente finito que o usuário possa explorar. As cenas desenvolvidas no GNT-Cyst 2.0 estão em relação direta com as telas apresentadas aos usuários, em que ele manipula as diferentes opções das telas através de cliques e/ou arrastos do mouse (manipulação direta). As transições entre as cenas, bem como o processo de controle dos resultados da simulação são feitos por meio de scripts escritos na linguagem C\#, suportados pela Unity $3 D$.

\subsection{Módulos}

Para o ensino fundamental foram retirados e adaptados conceitos de um livro didático [CANDIANI 2007], em que é abordado o tema do Experimento de Mendel, descrito por cruzamentos de ervilhas que podem gerar diferentes tipos de descendentes.

O objetivo é trabalhar com o aluno no simulador os resultados das combinações dos tipos de ervilha: verde, amarela e amarela híbrida. Clicando e arrastando para a área de combinação, o usuário escolhe o número de ervilhas que quer iniciar o processo e, em seguida, inicia a simulação. O resultado é mostrado numa tela seguinte, com a opção de voltar para a anterior e realizar um novo experimento. Este procedimento é o mesmo para todos os simuladores presentes no GNT-Cyst 2.0.

O módulo do ensino médio é composto por três submódulos: Noções de Probabilidade, Primeira Lei de Mendel e Segunda Lei de Mendel. Os conceitos trabalhados foram pesquisados e adaptados de um sítio com conteúdos de biologia [Só Biologia ].

Para a primeira Lei de Mendel, dois simuladores foram construídos: um para flores-maravilha e outro para sistema sanguíneo ABO. O assunto trabalhado com o primeiro é o da codominância de genótipos ${ }^{2}$, mostrando que todos eles podem se manter ativos quando combinados, o que resulta na cor rosa das flores, quando as outras são brancas ou vermelhas. Já para o segundo, tanto a codominância quanto a polialelia são trabalhados, com o simulador abordando as hemácias pertencentes aos tipos A, B, AB e

\footnotetext{
${ }^{1}$ Programa de computador que faz, ou não, uso de bibliotecas cujo objetivo é simplificar e abstrair o desenvolvimento de jogos eletrônicos.

${ }^{2}$ Termo utilizado para representar a constituição genética do indivíduo, indicando se a ervilha é homozigota ou heterozigota, por exemplo. Já o fenótipo se refere à características fisiológicas, como a cor das sementes das ervilhas.
} 
VI Congresso Brasileiro de Informática na Educação (CBIE 2017)

Anais dos Workshops do VI Congresso Brasileiro de Informática na Educação (WCBIE 2017)

O [Só Biologia ]. Os genótipos de cada uma delas são compostos e tem uma subdivisão diferente quando combinados.

Por fim, a segunda Lei de Mendel trabalha com a segregação independente de dois fatores. No caso, além da cor das ervilhas, trabalhados em módulos anteriores, agora também é possível observar outra característica delas: se são lisas ou rugosas [Só Biologia ]. O simulador, com as novas opções para escolha na combinação, permite obter ainda mais resultados que os da primeira Lei de Mendel.

\subsection{Avaliação com Usuários}

Um total de duas avaliações foram feitas com usuários-alvo, sendo a primeira numa versão anterior do GNT-Cyst 2.0, que se destinava apenas a alunos do ensino fundamental. A segunda avaliação, já com o software em seu estado atual, foi realizada com uma professora de biologia que trabalha com alunos do ensino fundamental e médio.

\subsubsection{Primeira Avaliação}

Os grupos foram de estudantes do $8^{\circ}$ e $9^{\circ}$ anos de uma instituição privada situada no município de Duque de Caxias, no Estado do Rio de Janeiro. A visita ocorreu no início do ano letivo de 2016.

Os grupos foram compostos da seguinte forma:

- Grupo 1: Quatro alunos do $8^{\circ}$ ano do ensino fundamental. Como estavam no início do ano, ainda não tinham estudado o conteúdo em sala de aula;

- Grupo 2: Cinco alunos do $9^{\circ}$ ano do ensino fundamental. Alguns deles já haviam visto o conteúdo no ano anterior e outros não, por virem de colégios diferentes.

Toda a avaliação, incluindo apresentação inicial, levou cerca de 20 minutos, acompanhado por uma orientadora educacional. De início, o propósito do software era explicado, bem como um pouco sobre o assunto abordado e o porquê de estar programado em computador poder ajudar.

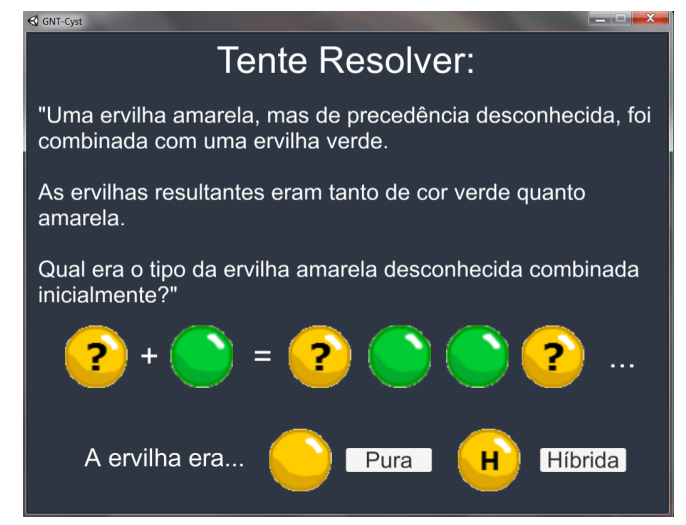

Figura 1. Tela de Desafio da Primeira Versão

A próxima etapa foi a experimentação pelos alunos, onde eventuais dúvidas sobre como operar surgiram e foram sanadas. As interpretações iniciais dos resultados foram 
VI Congresso Brasileiro de Informática na Educação (CBIE 2017)

Anais dos Workshops do VI Congresso Brasileiro de Informática na Educação (WCBIE 2017)

refeitas no quadro para solidificar um pouco da teoria, especialmente para aqueles que não tinham visto o assunto. Após todos os alunos ficarem confortáveis com o software, o desafio proposto no mesmo foi apresentado (Figura 1).

\subsubsection{Segunda Avaliação}

Com o término do desenvolvimento do GNT-Cyst 2.0, novas instituições de ensino foram buscadas para avaliações, especialmente as públicas. Contudo, não foi possível agendar devido à várias circunstâncias. Dessa forma, no final do ano letivo de 2016, o mesmo colégio participante da primeira avaliação foi visitado. Porém, pelo fato dos alunos já estarem em época de provas, a avaliação precisou ser rápida e feita com um professor.

Durante a conversa, toda a motivação e proposta para a construção do software foram explicadas, enquanto as funções iniciais do mesmo eram mostradas. Foi dado destaque a como a versão original foi expandida e de onde foi obtido o conhecimento técnico para a sua construção. Os resultados de ambas as avaliações compõem as considerações finais deste artigo.

\section{Apresentação do Software}

O GNT-Cyst 2.0 é uma aplicação desktop, necessitando ser baixado e executado na máquina do usuário. O mínimo requisitado para poder utilizá-lo é o Sistema Operacional Microsoft Windows 7 e resolução da tela de 1024x768. Sendo um software livre, ele pode ser livremente adquirido e utilizado por qualquer pessoa e instituição, desde que não alterem os créditos e não tentem comercializá-lo. A versão mais recente pode ser baixada em: https://github.com/eryckpedro/GNT-Cyst-2.0/blob/ master/versoes_executaveis/windows/GNT-Cyst-2.0_windows.rar

Ao abrir o arquivo executável, surge uma tela de configuração. Nela, o usuário deve escolher a resolução desejada na lista em Screen (respeitando a mínima exigida). Marcar a opção Windowed indica que o programa será executado em janela, caso contrário, ficará em tela cheia. Após esses passos, o software será inicializado ao clicar no botão "Play!". Um vídeo de demonstração do GNT-Cyst 2.0 pode ser visualizado em: https: / / youtu.be/zUsPhPIIZvU.

Após clicar "Play!", a tela do menu principal (Figura 2(a)) do GNT-Cyst 2.0 será mostrada. Nela, é possível escolher o módulo desejado para exploração (ensino fundamental ou médio), bastando clicar nos botões correspondentes. Quando um módulo é selecionado, a tela com suas opções é carregada.

No módulo do ensino fundamental (Figura 2(b)), as opções principais são de Iniciar Simulação e Resolver Desafio. A primeira leva para a tela de simulação do módulo, já a segunda trabalha com o desafio proposto no livro didático utilizado [CANDIANI 2007]. O módulo do ensino médio (Figura 2(c)) exibe um menu com seus submódulos e cada um deles tem opções similares aos do ensino fundamental, com os simuladores específicos de cada tópico abordado.

Os simuladores de todos os módulos são análogos. Na tela de combinação (Figura 2(d)), o usuário escolhe quais elementos deseja cruzar. Para isto, ele deve clicar e arrastar do painel de elementos aqueles que deseja trabalhar levando-os pro painel de combinações 
e encaixando-os nos ícones dos béquers. Deixar o ponteiro do mouse sobre cada elemento faz com que suas informações, como nome, alelo e tipo, sejam exibidas no painel à direita. Contudo, antes de poder gerar os resultados, um número de elementos precisa ser selecionado dentre 4,8 ou 16, no menu à esquerda do painel de combinações. O número escolhido sempre será o último botão a ser selecionado, ou seja, cliques consecutivos são sobrescritos. Feito isso, basta o usuário clicar no botão "Combinar!".

A tela de resultado (Figura 2(e)) é onde o usuário obtém os resultados da combinação realizada. Se desejar realizar outro experimento, basta voltar utilizando o botão "Combinar Novamente!". Aqui é importante salientar que no módulo do ensino fundamental, as ervilhas são geradas em ordem, respeitando apenas a proporção resultante. Já todos os simuladores do ensino médio, além de respeitarem a proporção, também implementam a probabilidade de surgir cada elemento, fazendo com que não tenha uma ordem fixa de geração (Figura 2(f)). Esta abordagem foi implementada com base nos currículos escolares para cada módulo.

\section{Considerações Finais}

Neste artigo, o GNT-Cyst 2.0 foi apresentado. Sendo um software educacional que aborda o conteúdo de genética, ele pode ser utilizado por alunos do ensino fundamental e médio, de acordo com os currículos educacionais vigentes. Ele é uma ferramenta de licença livre para uso e de simples requisitos computacionais, permitindo implementação em instituições públicas e privadas, bem como nos computadores pessoais de alunos e professores.

\subsection{Resultados das Avaliações}

Na primeira avaliação, ainda na primeira versão do GNT-Cyst 2.0, o grupo 1 mostrouse bastante atento durante todas as explicações sobre o programa e a teoria. Eles não responderam corretamente o desafio, mas justificaram de maneira coerente. A conclusão foi que, por ser um assunto novo, eles confundiram os termos de "pura"e "híbrida", pois só a escolha estava incorreta, mas a explicação não. Já o grupo 2 estava um pouco mais nervoso no início, não entendendo muito bem o propósito de estarem ali. Somente após todas as explicações é que decidiram interagir com o computador. Por questões de tempo, não foi possível realizar o desafio com eles.

Já na segunda avaliação, na conversa com a professora sobre a versão atual do GNT-Cyst 2.0, ela concordou que os temas abordados estavam bem selecionados, especialmente o do sistema sanguíneo ABO, pois o tema é muito presente em provas e pertencem aos exemplos mais concretos que os alunos conseguem entender. Ao ser perguntada se ela usaria o GNT-Cyst 2.0 em sala de aula, ela concordou de imediato. Disse que muitos alunos chegam a ir até ela perguntar possíveis temas para Trabalhos de Conclusão de Curso, mas ainda não tinha visto um software assim. Além disso, ela informou que seria muito bem aplicado naquela instituição de ensino pois eles tem televisores conectados a um computador em sala de aula e tornaria fácil uma apresentação, sem reservar o uso do laboratório.

Os resultados sugerem um interesse tanto pelos alunos quanto pelos professores na utilização dessa abordagem em sala de aula, pois eles mesmos citaram, de formas análogas, que ainda não tinham visto programas parecidos. Essa experiência permite-nos 
VI Congresso Brasileiro de Informática na Educação (CBIE 2017)

Anais dos Workshops do VI Congresso Brasileiro de Informática na Educação (WCBIE 2017)

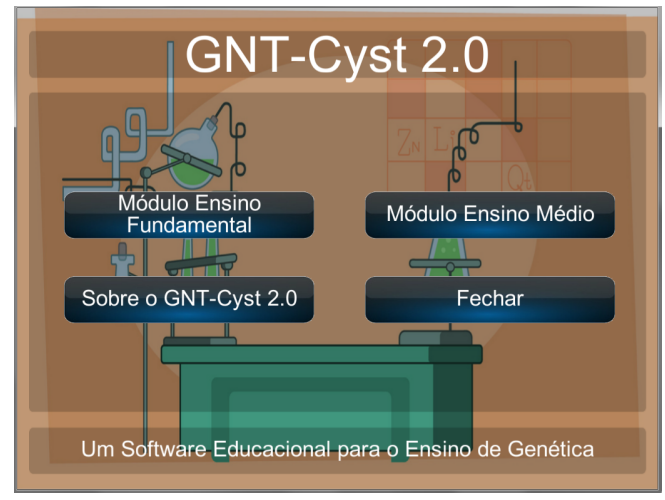

(a) Menu Principal

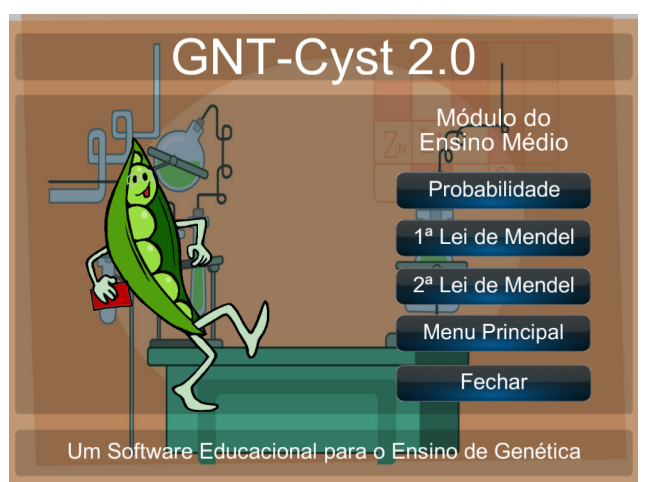

(c) Módulo Ensino Médio

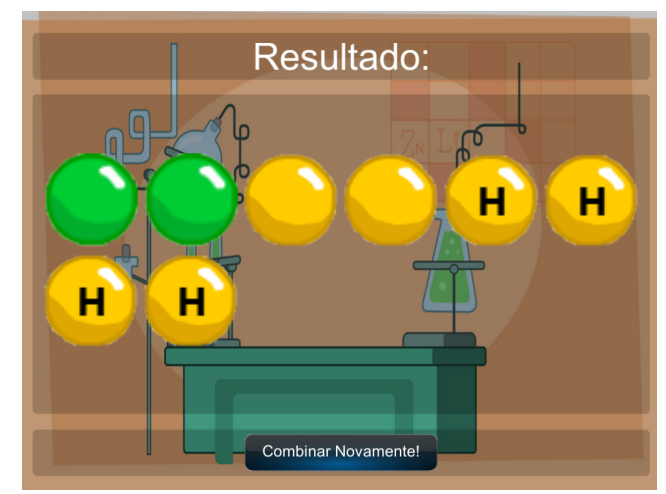

(e) Resultado - Ensino Fundamental (8 ervi- ( lhas resultantes)

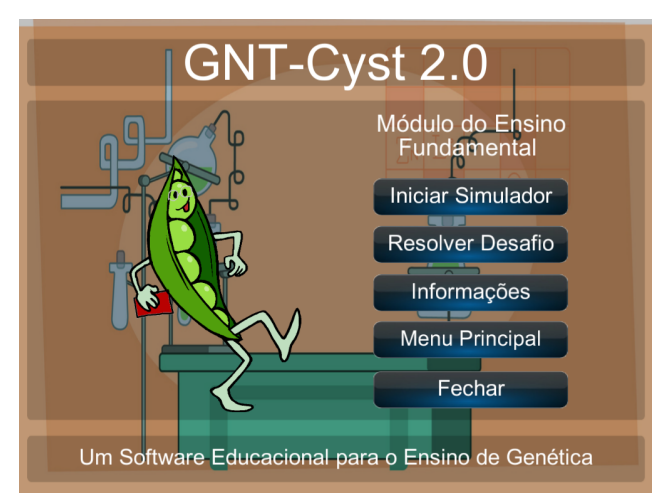

(b) Módulo Ensino Fundamental

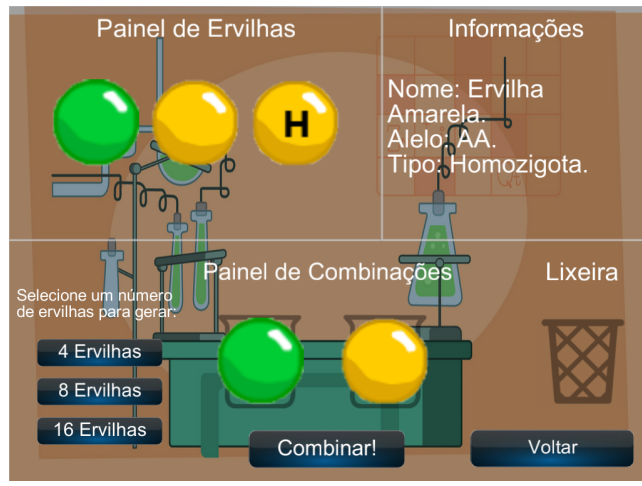

(d) Combinação - Ensino Fundamental

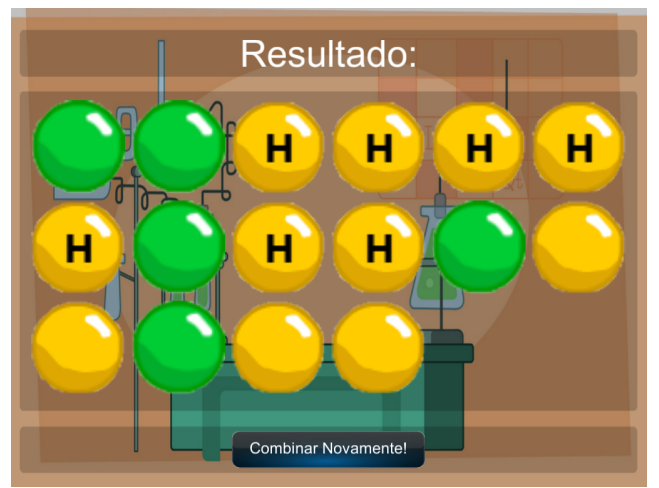

(f) Resultado - Ensino Médio (16 ervilhas resultantes)

Figura 2. Exemplos de telas do GNT-Cyst 2.0

pensar que o tema genética é uma área interessante de se investir uma vez que há alguma demanda para software como o aqui apresentado.

O GNT-Cyst 2.0 se encontra completo e passível de utilização em ambientes reais de ensino-aprendizagem. Novas versões do software estão sendo desenvolvidas na plataforma NetLogo [WILENSKY, U. 1999] a fim de proporcionar uma maior experimentação por parte dos usuários, bem como a apresentação dos resultados em outros formatos (gráficos, tabelas, etc.). 
VI Congresso Brasileiro de Informática na Educação (CBIE 2017)

Anais dos Workshops do VI Congresso Brasileiro de Informática na Educação (WCBIE 2017)

\section{Referências}

BERGER FILHO, R. L., SIMÕES PEREIRA, A. R., and MAIA, E. M. (1996). Parâmetros Curriculares Nacionais.

http://portal.mec.gov.br/seb/arquivos/pdf/ciencian.pdf (Acessado em 28/04/2017).

CANDIANI, G. e. a. (2007). Ciências 8 - Projeto Araribá. Editora Moderna, 2 edition.

CRUZ, C.D. et al. GBOL - Genética Básica OnLine. http: / / www • ufv • br/dbg/ gbol / gbol . htm (Acessado em 09/05/2017).

IORIOPETROVICH, A. C. e. a. (2014). TEMAS DE DIFÍCIL ENSINO E APRENDIZAGEM EM CIÊNCIAS E BIOLOGIA: EXPERIÊNCIAS DE PROFESSORES EM FORMAÇÃO DURANTE O PERÍODO DE REGÊNCIA. Revista da SBEnBio, (7).

MINISTÉRIO DA EDUCAÇÃO. Orientações Educacionais Complementares aos Parâmetros Curriculares Nacionais.

http://portal.mec.gov.br/seb/arquivos/pdf /

CienciasNatureza.pdf (Acessado em 28/04/2017).

MONTEIRO MARTINEZ, E., FUJIHARA, R., and MARTINS, C. (2008). SHOW DA GENÉTICA: UM JOGO INTERATIVO PARA O ENSINO DE GENÉTICA. Genética na Escola - Sociedade Brasileira de Genética.

OEIT - MIT. STAR:Genetics. http://star.mit.edu/genetics/index.html (Acessado em 09/05/2017).

Só Biologia. Biologia - Ensino Médio. http://www.sobiologia.com.br/ conteudos/Biologia/ (Acessado em 02/05/2017).

Unity Technologies. Unity3D. https : / / unity3d. com (Acessado em 02/05/2017).

VALENTE, J. A. (1998). Computadores e Conhecimento - Repensando a Educação. Universidade Estadual de Campinas, 2 edition.

WILENSKY, U. (1999). NetLogo. https://ccl.northwestern.edu/ net logo/ (Acessado em 22/05/2017). 